\title{
Downstream processing and characterization of polyhydroxyalkanoates (PHAs) produced by mixed microbial culture (MMC) and organic urban waste as substrate
}

\author{
Laura Lorini $^{1} \cdot$ Andrea Martinelli $^{1} \cdot$ Paolo Pavan $^{2} \cdot$ Mauro Majone $^{1} \cdot$ Francesco Valentino $^{1}$ (D \\ Received: 18 March 2020 /Revised: 20 May 2020 / Accepted: 22 May 2020 / Published online: 6 June 2020 \\ (C) The Author(s) 2020
}

\begin{abstract}
The utilization of food waste and sewage sludge as organic substrate from urban context for the synthesis of microbial polyhydroxyalkanoates (PHAs) has been only recently investigated at pilot scale. Within this context, two stabilization methods have been found for preserving the amount of PHA intracellularly produced by open mixed microbial culture (MMC): thermal drying and wet acidification of the biomass at the end of PHA accumulation process. The extracted PHA from the two differently stabilized biomasses was then characterized with regard to chemical composition, molecular weight, and thermal properties. The polymer contained two types of monomers, namely 3-hydroxybutyrate $(3 \mathrm{HB})$ and 3-hydroxyvalerate $(3 \mathrm{HV})$ at a relative percentage of 93.0-79.8 and 7.0-20.2 w/w, respectively. PHA extracted from wet-acidified biomass had higher average molecular weights $\left(M_{w}\right)$ of 370-424 kDa while PHA recovered from thermally stabilized dried biomass had a 3-fold lower $M_{w}$ (on average). The PHA decomposition temperatures $T_{d}{ }^{10 \%}$ and $T_{d}{ }^{\max }$ were in the range $260-268{ }^{\circ} \mathrm{C}$ and $269-303{ }^{\circ} \mathrm{C}$, respectively, not dependent on the monomeric composition or molecular weight. Thermal properties such as melting temperature $\left(T_{m}{ }^{1}{ }^{132}\right.$ $\left.150^{\circ} \mathrm{C} ; T_{m}{ }^{2} 155-167^{\circ} \mathrm{C}\right)$ and melting enthalpy $(26-70 \mathrm{~J} / \mathrm{g})$ were quantified in a relatively broad range according to the different stabilization-extraction method and obtained composition.
\end{abstract}

Keywords Polyhydroxyalkanoates (PHAs) $\cdot$ Mixed microbial culture $(\mathrm{MMC}) \cdot$ Downstream processing $\cdot$ Organic fraction of municipal solid waste $(\mathrm{OFMSW}) \cdot$ Molecular weight $\left(M_{w}\right)$

\section{Introduction}

Polyhydroxyalkanoates (PHAs) are one of the most interesting biopolymers due to their mechanical properties and biodegradability. Their chemomechanical properties have been extensively discussed [1], but the same attention has not been dedicated to biodegradability aspects. The marketed product derived from pure strain; its biodegradation has been related to those microorganisms that could secrete extracellular PHA depolymerase even though other factors such as the environmental condition and/or PHA properties (e.g., composition,

Francesco Valentino

francesco.valentino@uniroma1.it

1 Department of Chemistry, "La Sapienza" University of Rome, P.le Aldo Moro 5, 00185 Rome, Italy

2 Department of Environmental Science, Informatics and Statistics, "Cà Foscari”" University of Venice, Via Torino 155, 30170 Venezia Mestre, Italy crystallinity, additives) could affect the PHA degradation [2]. As an example, the effect of chemical structure on PHA biodegradability has been investigated by Weng et al. [3]: according to ISO $14855-1$, the controlled composting conditions showed that higher 3-hydroxyvalerate $(3 \mathrm{HV})$ content corresponded to higher biodegradability. In the form of composites (together with waste wood sawdust fibers), the ASTM D5338-98 and ISO 20200-2004 standard methods revealed that the presence of fibers favored the physical disintegration of PHA, increasing the biodegradation rate of the polymeric matrix [4]. To the best knowledge of the authors, there are no biodegradability data in the literature for PHA synthetized by mixed microbial culture (MMC). The approach of MMC technology consists in the exploitation of organic wastes as feedstock [5, 6]. In addition, MMC technology involves the use of waste-activated sludge (always available in municipal wastewater treatment plants, WWTPs) as inoculum that needs to be enriched in microorganisms with high polymer accumulation capacity. PHA-storing organisms can grow by applying 
aerobic dynamic feeding conditions (ADF) through the wellknown feast-famine regime [7]. In the last decade, MMCPHA production using different types of waste has been the topic of several applied researches; moreover, recent investigation has been conducted at pilot scale to demonstrate the technical feasibility of the technology $[8,9]$. In particular, PHA production from the organic fraction of municipal solid waste (OFMSW) has been assessed in order to quantify the process PHA productivity (g PHA/L day) potentially achievable and final polymer quality, also in consideration of a possible integration in the existing wastewater WWTP [10-12]. These are fundamental aspects for MMC-derived PHA commercialization and relative market scenario, which do not exist yet. In the view of a larger-scale MMC-based process, PHA recovery and, more in general, the whole downstream processing from PHA-rich biomass stabilization to PHA extraction are still the bottlenecks of the entire production chain. A recent review summarizes the sustainable approaches and latest developments for the downstream processing [13], emphasizing the environmental unsuitability of chlorinated solvents. With particular attention for the MMC PHA-rich biomass, several non-chlorinated solvents have been firstly exploited [14] together with a biomass stabilization protocol, where a temperature range of $120-160{ }^{\circ} \mathrm{C}$ was adopted in order to preserve the polymer quality. The latter might be also improved by optimization of time, temperature, and concentrations of reagents in the purification steps as a function of PHA composition [15]. Moreover, PHA content in the biomass at the end of the accumulation step has to be preserved to maximize the efficiency and the productivity of the process. In addition, recovery methods need to be flexible towards conditions that may be readily tuned to a range of polymer types [14]. For application and realization of bioplastic products, it is necessary to obtain a polymer with specific chemical, physical, and mechanical properties. The mechanical properties of PHA are good when the average molecular weight $\left(M_{w}\right)$ is higher than $400 \mathrm{kDa}$, and specifically thermoplastic applications may require $M_{w}$ higher than $600 \mathrm{kDa}$. Molecular weights typically range between 200 and $3000 \mathrm{kDa}$, and the distribution can be affected by the method of accumulating PHA in the biomass, the method for PHA recovering, and PHA processing into end-user products [15]. The few studies on chemomechanical and thermal characterization of MMCPHA have been reviewed by Laycock and coworkers [15]. It has been noted that there is often a higher melting temperature $\left(T_{m}\right)$ and a lower enthalpy of melting for MMC-PHA than those of pure culture-derived PHA [16]. This is probably due to the formation of block copolymers or polymer blends which in turn is a consequence of the feeding strategies adopted in MMC systems. The pulse feeding causes frequent variability in substrate concentrations that leads to a block formation depending on the substrate availability (e.g., 3hydroxyvalerate synthesis in the presence of propionate)
[17]. Thermogravimetric analysis on MMC-PHA samples showed a similar thermal stability (with decomposition temperatures of about $270{ }^{\circ} \mathrm{C}$ ) to the commercial poly-3hydroxybutirate $[\mathrm{P}(3 \mathrm{HB})]$ and poly-3-hydroxybutyrate-co-3hydroxyvalerate [P(3HB-co-3HV) $(10 \mathrm{~mol} \% \mathrm{HV})]$ [18]. Besides, the crystallization rate slows down as $3 \mathrm{HV}$ content increases [1]. Arcos-Hernández et al. have conducted a study in which PHA produced with different $3 \mathrm{HV}$ content were characterized, evaluating the possible effects on polymer properties [19]. In terms of mechanical properties, it has been demonstrated that the MMC-PHA Young's modulus (779$2893 \mathrm{MPa}$ ) increased significantly when the $3 \mathrm{HV}$ content was lower than $40 \mathrm{~mol} \%$; furthermore, the elongation to break of all but one of the samples was in the range of $3-6 \%$ which is similar to that expected for $\mathrm{P}(3 \mathrm{HB})$ (brittle and stiff) [19]. In general, the progressive incorporation of $3 \mathrm{HV}$ in PHA from pure culture, mainly referred to commercial polymer, brings about a constant increase of $\varepsilon_{b}$ from about $2.5 \mathrm{~mol} \%$ at $3 \mathrm{HB}$ equal to $100 \mathrm{~mol} \%$, to $44 \mathrm{~mol} \%$ at $3 \mathrm{HB}$ equal to $60 \mathrm{~mol} \%$. The elongation to break of samples obtained from MMC remains constant to about $3 \mathrm{HB} 65 \mathrm{~mol} \%\left(\varepsilon_{b} \approx 3 \%\right)$ and shows a small increase from 54 to $28 \mathrm{~mol} \% 3 \mathrm{HB}\left(\varepsilon_{\mathrm{b}} \approx 5 \%\right)$ [20].

Hence, it is important to demonstrate that the quality of MMC-derived PHA can consistently meet the standards required for use in commercially interesting plastic applications. Thinking of an implementation at industrial scale, it is worthwhile to identify a method for biomass stabilization that allows to enhance and preserve the thermal and mechanical properties of the PHA and to conduct the recovery step at a later time and/or in a different site. In this regard, a biomass stabilization method has been conducted and optimized at pilot scale, in the context of a MMC-PHA production and fermented mixture of OFMSW and thickened wasteactivated sludge (WAS) as urban waste feedstock [11]. Then, the stabilized biomass was subjected to downstream processing. The recovered polymer, entirely produced from renewable resources, was extensively characterized for thermal and chemical properties as well as $M_{w}$ determination.

\section{Materials and methods}

Within the pilot platform of Treviso (northeast Italy), the PHA was produced from a feedstock composed by a mixture of the liquid slurry coming from squeezing of the OFMSW and waste activated sludge (WAS) from treatment of urban wastewater. The main process setup (extensively described in Valentino et al.[11]) was a first anaerobic fermentation reactor (380 L) for PHA precursor production (volatile fatty acid, VFA), a second aerobic reactor (sequencing batch reactor, SBR; $100 \mathrm{~L}$ ) for biomass cultivation, and a third fed-batch aerobic reactor $(70-90 \mathrm{~L})$ for PHA accumulation within cellular wall (40-50 wt\%). The following approach for PHA 
maintenance within cellular wall (or biomass stabilization), extraction, and final characterization is explained in the following paragraph and depicted in Fig. 1.

\subsection{PHA maintenance and biomass stabilization tests}

The maintenance of PHA within cellular walls has been assessed in the biomass stabilization tests carried out with PHA-rich biomass taken at the end of accumulation step. Each trial was carried out in $0.2-\mathrm{L}$ reactor, filled with biomass from pilot-scale plant. These tests were performed in order to find the best strategy for maintaining constant the PHA level in the cells, or close to the concentration quantified at the end of accumulation step, before the downstream processing. Each test was performed for a relatively long period of $48 \mathrm{~h}$. The PHA concentration was always related to the initial one, determined at the end of accumulation. Five anaerobic conditions were explored:

(a) Anaerobic starvation by stopping the aeration system.

(b) Alkaline treatment by adding $\mathrm{NaOH} 0.2 \mathrm{M}$ solution (up to $\mathrm{pH}$ 12.0).

(c) Acidic treatment by adding $\mathrm{H}_{2} \mathrm{SO}_{4}$ down to $\mathrm{pH} 2.0$.

(d) Oxidative treatment by adding $0.1 \mathrm{v} / \mathrm{v} \mathrm{NaClO}$ solution ( $5 \%$ active $\mathrm{Cl}_{2}$ ).

(e) Thermal treatment at $145{ }^{\circ} \mathrm{C}$ for 30 min followed by overnight drying at $70{ }^{\circ} \mathrm{C}$.

In the first four conditions $(\mathrm{a}-\mathrm{d})$, the biomass was maintained under mixing for the whole test period. In the last condition (e), the biomass was centrifuged at the end of accumulation, before the starting of thermal stabilization procedure. The determination of PHA concentration was performed by taking the humid pellet at the end of $145^{\circ} \mathrm{C}$ pretreatment and the dried material (final sample), both re-suspended at the same initial total suspended solid (TSS) concentration. Each stabilization test was performed in triplicate.

\subsection{PHA extraction and recovery}

Five different batches (B1-a, B2-a, B3-a, B4-a, B5-a), with PHA content more than $40 \% w / w$ on dry weight, have been selected to perform polymer extraction and characterization. Chloroform extraction and $\mathrm{NaClO}$ oxidation have been applied as standard methods. Both extractions have been conducted to recover PHA from dry PHA-rich biomass obtained after thermal stabilization. The $\mathrm{NaClO}$ treatment has been also carried out on acid-stabilized wet biomass (B2-a, B2-b).

\subsubsection{Chloroform extraction}

A 2-5-g sample of dried PHA-rich biomass (thermally stabilized) was put into a glass fiber extraction thimble placed inside of a $50-\mathrm{mL}$ borosilicate glass Soxhlet extractor, equipped with a $100-\mathrm{mL}$ borosilicate glass flask, filled with $70 \mathrm{~mL}$ of chloroform, a bubble condenser, and a boiler, in order to keep the solvent at boiling temperature for $24 \mathrm{~h}$. The PHA solution was cooled down at room temperature and then transferred into a crystallizer of $\varnothing=8 \mathrm{~cm}$, in order to obtain a polymer film by solvent evaporation under fume hood.

\subsubsection{Hypochlorite oxidation}

Dried PHA-rich biomass (thermally stabilized) or acidstabilized wet biomass was suspended in a $\mathrm{NaClO}$ solution

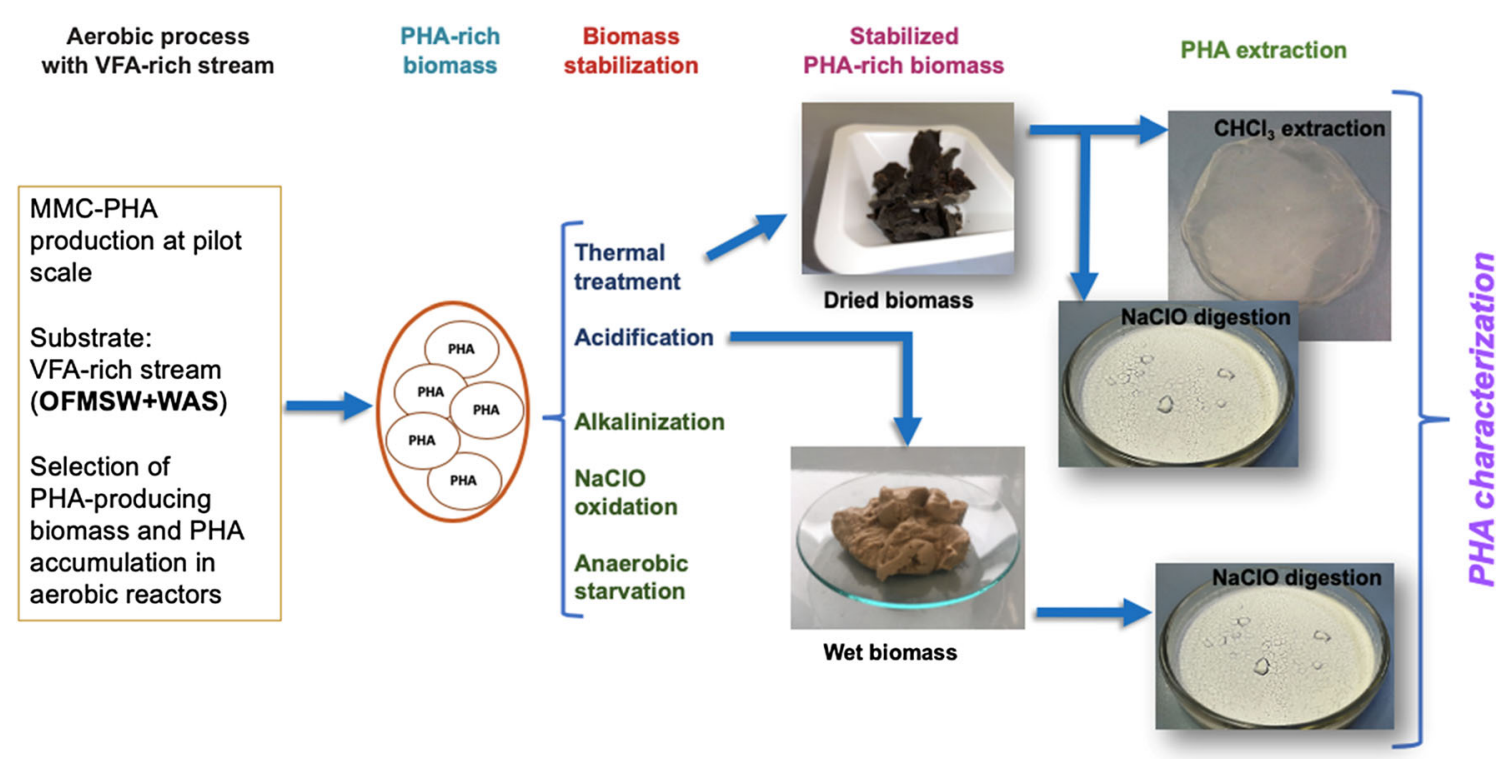

Fig. 1 Methodology applied to PHA-rich biomass for its stabilization (or PHA maintenance within cellular wall), PHA extraction, and final characterization 
(1.5\% active $\left.\mathrm{Cl}_{2}\right)$. The suspension was kept under magnetic stirring overnight, centrifuged at $8500 \mathrm{rpm}$ for $20 \mathrm{~min}$, and, then, washed 3 times with distilled water. Wet pellet was finally transferred into a crystallizer and oven-dried at $70{ }^{\circ} \mathrm{C}$.

\subsection{PHA characterization}

\subsubsection{PHA content and composition determination (GC-FID)}

Approximately $3.5 \mathrm{mg}$ of dried biomass or $5.0 \mathrm{~mL}$ of resuspended samples (wet and dried thermally treated biomasses) was suspended in $2 \mathrm{~mL}$ of acidified methanol solution (at $3 \% v / v \mathrm{H}_{2} \mathrm{SO}_{4}$ ) containing benzoic acid (at $0.005 \% \mathrm{w} / v$ ) as internal standard and $1 \mathrm{~mL}$ of chloroform in a screw-capped test tube. Then, an acid-catalyzed methanolysis of the PHA occurred, and the released methyl esters were quantified by gas chromatography (GC-FID Perkin Elmer 8410) according to the method described in Braunegg et al. [21]. The relative abundance of $3 \mathrm{HB}$ and $3 \mathrm{HV}$ monomers was determined using a commercial $\mathrm{P}(3 \mathrm{HB}-\mathrm{co}-3 \mathrm{HV})$ copolymer with a $3 \mathrm{HV}$ content of $5 \mathrm{wt} \%$ (Sigma-Aldrich, Milan, Italy) as reference standard. The $3 \mathrm{HV}$ content in PHA was calculated as the ratio of $3 \mathrm{HV}$ and $(3 \mathrm{HB}+3 \mathrm{HV})$ monomers (as $\mathrm{wt} \%)$.

\subsubsection{Capillary viscosimetry}

Two hundred milligrams of dried polymer, extracted with $\mathrm{NaClO}$ or solubilized by chloroform, was suspended into a $50-\mathrm{mL}$ borosilicate glass flask, filled with $50 \mathrm{~mL}$ of chloroform and kept at boiling temperature for $24 \mathrm{~h}$. Possible nonsoluble residues were filtered with GF/D Whatman ${ }^{\circledR}$ microfiber glass filters, and the PHA solution was poured into a crystallizer of $\varnothing=8 \mathrm{~cm}$, in order to obtain a polymer film by solvent evaporation under fume hood. A volume of $25 \mathrm{~mL}$ of PHA solution at the concentration of $0.5 \% \mathrm{w} / \mathrm{v}$ in chloroform were prepared for all the samples of extracted polymer.

The equipment for the measure of the gravimetric flow time of each solution was composed by a SCHOTT AVS 350 viscosimeter with AVS/SHT sensor, a LAUDA CD15 thermostatic bath (working at $30{ }^{\circ} \mathrm{C}$ ), and a SCHOTT GERÄTE Ubbelohde capillary viscosimeter (ID $=0.46 \mathrm{~mm}$ ).

For each sample, $15 \mathrm{~mL}$ of solution $0.5 \% \mathrm{w} / \mathrm{v}$ was transferred in the Ubbelohde capillary viscosimeter, and the flow time was measured through the optical sensor. Then, at least 4 dilutions were made directly in the viscosimeter by adding predetermined aliquots of solvent. From the flow time of each solution, the intrinsic viscosity $[\eta]$ of polymer samples was determined. The viscometry average molecular weight $\left(M_{v}\right)$ was calculated according to the Mark-Houwink equation:

$M_{v} \rightarrow[\eta]=K \times M_{v}{ }^{\alpha}$

with $K=7.7 \times 10^{-5}$ and $\alpha=0.82[22]$

\subsubsection{Thermogravimetric analysis}

The thermal stability of the samples was evaluated by thermogravimetric analysis (TGA) using a Mettler TG50 thermobalance. Approximately $5 \mathrm{mg}$ of dried samples was weighted on the balance. The analysis was conducted in nitrogen flow $(20 \mathrm{ml} / \mathrm{min})$ by heating the samples from 30 to $500{ }^{\circ} \mathrm{C}$ at $10{ }^{\circ} \mathrm{C} / \mathrm{min}$.

\subsubsection{Differential scanning calorimetry}

The thermal properties of the PHA samples were characterized by a differential scanning calorimeter Mettler Toledo differential scanning calorimetry (DSC) 822e. All the experiments were carried out under $\mathrm{N}_{2}$ flux $(30 \mathrm{ml} / \mathrm{min})$ on about 3-6 $\mathrm{mg}$ of polymer, weighted in aluminum pans. Unfortunately, because of the possible presence of chlorine traces, the samples treated with $\mathrm{NaClO}$ were not analyzed by DSC. The instrument furnace, in fact, has silver components which could be damaged by halogens.

Then, in order to evaluate the intrinsic thermal properties of the dry PHA obtained by solubilization in chloroform, unaffected by the previous sample treatments and thermal history, the following temperature program was selected:

1. A heating scan at $10{ }^{\circ} \mathrm{C} / \mathrm{min}$ from RT to $190{ }^{\circ} \mathrm{C}$.

2. A rapid cooling at $30{ }^{\circ} \mathrm{C} / \mathrm{min}$ from 190 to $70{ }^{\circ} \mathrm{C}$ and annealing at $70{ }^{\circ} \mathrm{C}$ for $30 \mathrm{~min}$.

3. Cooling from 70 to $30{ }^{\circ} \mathrm{C}$ and second heating up to $190{ }^{\circ} \mathrm{C}$ at $10{ }^{\circ} \mathrm{C} / \mathrm{min}$.

The first heating is necessary to erase all the previous sample history. Then, in the isothermal annealing, all the analyzed samples crystallized and reached the maximum crystallinity, independently from chemical composition or molecular weight. In fact, in the last heating ramp, no cold crystallization occurred. The sample crystallinity $\left(X_{c}\right)$ was evaluated from the equation:

$X_{c}=100 \times \Delta H_{m} /\left(\Delta H_{m}{ }^{0} \times\right.$ purity $)$

where $\Delta H_{m}$ is the melting enthalpy obtained from the first or second DSC heating scan and $\Delta H_{m}{ }^{0}=146 \mathrm{~J} / \mathrm{g}$ is the enthalpy of fusion of $100 \%$ crystalline PHB sample [23].

\section{Results and discussion}

\subsection{PHA trends and its maintenance within cellular walls}

The stabilization tests showed interesting results during the $48 \mathrm{~h}$ of monitoring. Indeed, the comparison of PHA content 
data collected for each inhibition test shows that there was not a significant decrease of the polymer for $48 \mathrm{~h}$ following the addiction of $\mathrm{H}_{2} \mathrm{SO}_{4}$ (97 wt $\%$ of initial content) (Fig. 2a), demonstrating that the agent is suitable for microbial activity quenching and PHA stabilization. The treatment with $\mathrm{NaClO}$ could be considered also acceptable with a reduction of $19 \mathrm{wt} \%$ of initial polymer content. Shorter time can be also taken into account since the decrease of the PHA content was lower: no PHA loss for $\mathrm{H}_{2} \mathrm{SO}_{4}$ treatment, around $10 \mathrm{wt} \%$ of PHA loss for the oxidative $\mathrm{NaClO}$ treatment within the first $4 \mathrm{~h}$.

Then, adding $\mathrm{H}_{2} \mathrm{SO}_{4}$ up to $\mathrm{pH} 2.0$ did not affect the PHA content, as the literature suggests [24], although the possible effects on the molecular weight were investigated, as shown later in further discussion. On the contrary, it is important to consider that, by adding a strong oxidizing agent $(\mathrm{NaClO})$, besides of a slight decrease of initial content, a reduction of molecular weight could occur. The anaerobic treatment and the addition of $\mathrm{NaOH}$ were not effective, showing a PHA loss higher than $40 \%$ from $18 \mathrm{~h}$. Even in these cases, shorter stabilization time (up to $4 \mathrm{~h}$ ) corresponded to lower PHA loss. However, compared with $\mathrm{H}_{2} \mathrm{SO}_{4}$ and $\mathrm{NaClO}$ treatment, alkaline and anaerobic stabilization methods were less effective. The polymer consumption under anaerobic conditions was not unexpected since dynamic conditions, such as those
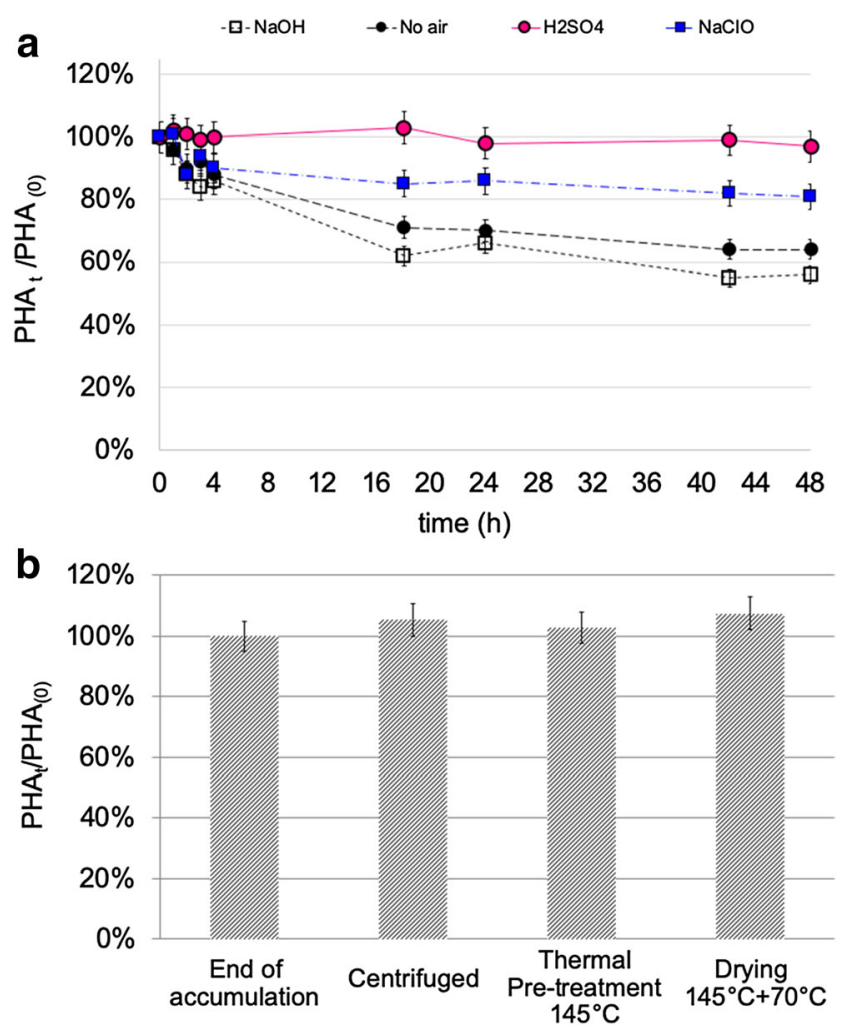

Fig. 2 Relative PHA content variation measured during $48 \mathrm{~h}$ after the beginning of the stabilization tests (a). Relative PHA content variation measured during thermal treatments, both with and without thermal shock (b) caused by alternate redox conditions (anaerobic/anoxic/aerobic), have been used to sustain the enrichment of PHA-storing microorganisms [6]. Even though the present biomass was selected under fully aerobic environment, it maintained the capability of polymer degradation under anaerobic conditions. In the case of $\mathrm{NaOH}$, the obtained result could be expected, because the base-catalyzed hydrolysis of polyester chain may possibly occur [25]. Thermal stability has been also reported to be negatively affected by $\mathrm{NaOH}$ solution, even in comparison with oxidative biomass treatment $(\mathrm{NaClO})$ [26].

The results of the thermal treatments are reported in Fig. 2b. It is possible to highlight that PHA content is completely preserved until the end of the drying step, in agreement with the observations of Bengtsson et al. [8]. Therefore, during the first period of this work, thermal treatment (including thermal shock at $145^{\circ} \mathrm{C}$ for $30 \mathrm{~min}$ ) has been applied at pilot scale at the end of several batch accumulation tests (including B1-a, B2-a, B3-a, B4-a, B5-a), in order to produce PHA for further extraction and characterization. Moreover, during a second period of the study, the acidification has been applied and the PHA from two batches (B1-b, B2-b) has been extracted and characterized, in order to compare the results of both stabilization methods.

\subsection{Extraction performances}

Chlorinated compounds $[17,27,28]$ or a mixture of chlorinated and non-chlorinated solvents [29] are consolidated extractive agents for PHAs from MMCs. In particular, chloroform is always used in benchmark protocols because it does not damage polymer structure and molecular weight, solubilizing the PHA inside the cellular membranes at low temperature [30]. In previous studies [26, 31], disruption of non-PHA cell material (NPCM) was obtained by using a $\mathrm{NaClO}$ solution in different conditions (concentration and retention time) with good recovery and purity level (higher than $90 \mathrm{wt} \%$ ). In this study, both chloroform extraction and $\mathrm{NaClO}$ digestion have been used as consolidated methods for PHA recovery. The first set of extraction tests has been carried out on dry PHArich biomass, thermally stabilized at the end of the accumulation step, and the $\mathrm{NaClO}$ digestion has been applied also on an acid-stabilized wet biomass. In this case, the extraction has been conducted on the wet centrifuged biomass, in order to skip the drying step and compare the results with those from thermally stabilized biomass, evaluating possible differences and effects on the polymer properties.

Results obtained by GC-FID analysis conducted on extracted samples (Table 1) show that both the extraction methods allowed to reach satisfying performances in terms of purity, with an average value of $93.5 \pm 0.8 \% \mathrm{w} / \mathrm{w}$ and $88.1 \pm 4.9 \% \mathrm{w} / \mathrm{w}$ for $\mathrm{CHCl}_{3}$ and $\mathrm{NaClO}$, respectively, and recovery yield of $86.8 \pm 3.9 \% \mathrm{w} / \mathrm{w}$ and $78.2 \pm 7 \% \mathrm{w} / \mathrm{w}$ for $\mathrm{CHCl}_{3}$ and $\mathrm{NaClO}$, respectively. The variability of the $\mathrm{HV}$ 
Table 1 Extraction performances of thermally stabilized and acid-stabilized samples determined by GC-FID analysis

\begin{tabular}{|c|c|c|c|c|c|c|c|}
\hline Sample & $\begin{array}{l}\text { PHA content in raw } \\
\text { biomass }(\% w / w)\end{array}$ & $\begin{array}{l}\mathrm{HV} \text { content of PHA in raw } \\
\text { biomass }(\% w / w)\end{array}$ & Pre-treatment & Extraction & Purity $(\% w / w)$ & Recovery $(\% w / w)$ & HV content $(\% w / w)$ \\
\hline \multirow[t]{2}{*}{ B 1-a } & \multirow[t]{2}{*}{$56.1 \pm 4.4$} & \multirow[t]{2}{*}{$18.6 \pm 0.1$} & \multirow[t]{10}{*}{ Thermal drying } & $\mathrm{CHCl}_{3}$ & $92.9 \pm 6.1$ & $80.5 \pm 5.3$ & $19.2 \pm 0.1$ \\
\hline & & & & $\mathrm{NaClO}$ & $97.2 \pm 0.7$ & $75.4 \pm 0.5$ & $17.7 \pm 0.2$ \\
\hline \multirow[t]{2}{*}{ B 2-a } & \multirow[t]{2}{*}{$45.8 \pm 2.3$} & \multirow[t]{2}{*}{$7.7 \pm 0.4$} & & $\mathrm{CHCl}_{3}$ & $95.2 \pm 1.1$ & $97.9 \pm 1.1$ & $7.7 \pm 0.2$ \\
\hline & & & & $\mathrm{NaClO}$ & $87.0 \pm 2.1$ & $83.5 \pm 2.0$ & $7.0 \pm 0.1$ \\
\hline \multirow[t]{2}{*}{ B 3-a } & \multirow[t]{2}{*}{$39.6 \pm 4.4$} & \multirow[t]{2}{*}{$13.0 \pm 0.7$} & & $\mathrm{CHCl}_{3}$ & $91.5 \pm 1.4$ & $89.6 \pm 1.1$ & $14.9 \pm 0.4$ \\
\hline & & & & $\mathrm{NaClO}$ & $75.2 \pm 2.6$ & $52.8 \pm 2.2$ & $13.9 \pm 0.1$ \\
\hline \multirow[t]{2}{*}{ B 4-a } & \multirow[t]{2}{*}{$38.7 \pm 4.8$} & \multirow[t]{2}{*}{$13.4 \pm 0.6$} & & $\mathrm{CHCl}_{3}$ & $92.4 \pm 3.0$ & $75.4 \pm 2.5$ & $13.6 \pm 0.2$ \\
\hline & & & & $\mathrm{NaClO}$ & $80.3 \pm 4.1$ & $85.6 \pm 4.4$ & $14.0 \pm 0.3$ \\
\hline \multirow[t]{2}{*}{ B 5-a } & \multirow[t]{2}{*}{$42.3 \pm 1.2$} & \multirow[t]{2}{*}{$22.8 \pm 0.1$} & & $\mathrm{CHCl}_{3}$ & $95.4 \pm 9.4$ & $90.4 \pm 8.9$ & $20.2 \pm 0.3$ \\
\hline & & & & $\mathrm{NaClO}$ & $100.9 \pm 4.1$ & $93.9 \pm 3.8$ & $19.7 \pm 0.3$ \\
\hline B $1-b$ & $40.1 \pm 1.3$ & $13.4 \pm 0.3$ & Wet acidification & $\mathrm{NaClO}$ & $95.8 \pm 2.1$ & $90.0 \pm 1.9$ & $13.0 \pm 0.1$ \\
\hline B 2-b & $45.4 \pm 0.5$ & $13.7 \pm 0.1$ & & $\mathrm{NaClO}$ & $97.5 \pm 1.4$ & $91.8 \pm 2.5$ & $13.6 \pm 0.1$ \\
\hline
\end{tabular}

${ }^{\text {a }}$ Acid-stabilized wet biomass

content among the samples is probably a consequence of the wide period of time in which the biomass was collected; in fact, the different batches have been produced during 8 months of operation, so that the seasonality effect on the substrate composition and on the temperature has to be taken into account. On the other hand, both the recovery methods preserved the same $3 \mathrm{HV}$ content after the extraction tests. According to the extraction performances, there is the evidence that the stabilization method used at the end of the accumulation step did not affect the PHA recovery process from the biomass. In fact, similar PHA purity and recovery have been obtained for each biomass treatment.

\subsection{Thermogravimetric analysis}

Thermogravimetric analysis allowed to determine important characteristics of the polymers, such as decomposition temperatures and related thermal stability, as well as to confirm GC-FID data on polymer purity. Indeed, according to Hahn and Chang [32], it is possible to estimate the polymer content in the samples from the main weight loss occurring between 250 and $320{ }^{\circ} \mathrm{C}$ [32]. The results of the TGA experiments, including the PHA content, the temperatures at $10 \%$ decomposition $\left(T_{d}{ }^{10 \%}\right)$, and the temperature at maximum decomposition rate $\left(T_{d}{ }^{\max }\right)$, are reported in Table 2. Moreover, the TGA thermograms showed that all the impurities were consisted in inorganic material, since residual weight remained at the highest temperature.

The comparison of the results shows that PHA thermal stability was affected by the extraction agent used. Oxidative treatment produced samples with lower thermal stability than that from chloroform extraction for all thermally stabilized samples. In fact, the average $T_{d}{ }^{10 \%}$ and $T_{d}{ }^{\max }$ of $\mathrm{CHCl}_{3}$-extracted samples were $272 \pm 3{ }^{\circ} \mathrm{C}$ and $297 \pm 3{ }^{\circ} \mathrm{C}$ while for
$\mathrm{NaClO}$-extracted samples, the corresponding values were $259 \pm 3{ }^{\circ} \mathrm{C}\left(T_{d}{ }^{10 \%}\right)$ and $278 \pm 3{ }^{\circ} \mathrm{C}\left(T_{d}{ }^{\max }\right)$, respectively. Compared with the thermally stabilized samples, the PHA samples extracted with oxidative $\mathrm{NaClO}$ treatment from wetacidified biomass showed higher thermal stability, with an average $T_{d}{ }^{10 \%}$ and $T_{d}{ }^{\max }$ at $269 \pm 1{ }^{\circ} \mathrm{C}$ and $291 \pm 2{ }^{\circ} \mathrm{C}$, respectively.

Overall, such values indicated the high thermal stability of the polymer, comparable or higher to those observed in other studies on MMC-PHA (Table 2) and on commercial P(3HBco-3HV) $\left(T_{d}^{\max } 256-290{ }^{\circ} \mathrm{C}[33]\right)$.

Regarding the effect of $\mathrm{HV}$ content on the thermal stability, the available data are contradictory, and it does not allow to enunciate a statement. The sample B2-a was characterized by lower HV content $(7.7 \mathrm{wt} \%)$ compared with others, and it exhibited higher $T_{d}{ }^{10 \%}\left(278{ }^{\circ} \mathrm{C}\right)$ and $T_{d}^{\max }\left(303{ }^{\circ} \mathrm{C}\right)$ values. However, literature data show that homopolymer $\mathrm{P}(3 \mathrm{HB})$ ( $0 \mathrm{wt} \%$ HV content) may have a wide range of $T_{d}{ }^{\max }(268-$ $\left.290{ }^{\circ} \mathrm{C}\right)$, comparable with $\mathrm{P}(3 \mathrm{HB}-\mathrm{co}-3 \mathrm{HV})$ of this study with $\mathrm{HV}$ content roughly between 13 and $20 \mathrm{wt} \%$.

\subsection{Viscosimetry average molecular weight}

The determination of viscosimetry average molecular weight $\left(M_{v}\right)$ of each extracted sample was carried out to check possible polymer chain degradation due to the use of $\mathrm{NaClO}$ to disrupt NPCM. The results, reported in Fig. 3, were compared with that obtained from the PHA extracted from the biomass by chloroform, considered the benchmark sample, as discussed above.

The values reported in Fig. 3 showed that there is not a significant difference between the two applied extraction methods on thermally stabilized biomass samples. 
Table 2 Comparison between PHA purity determined by GC-FID and TGA analysis; decomposition temperatures determined by TG thermograms

\begin{tabular}{|c|c|c|c|c|c|c|c|}
\hline Sample & Feedstock & Pre-treatment & Extraction & TGA purity $(\% w / w)$ & $T_{d}^{10 \%}\left({ }^{\circ} \mathrm{C}\right)$ & $T_{d}^{\max }\left({ }^{\circ} \mathrm{C}\right)$ & References \\
\hline B $1-\mathrm{a}$ & \multirow[t]{9}{*}{ OFMSW-WAS mixture } & Thermal drying & $\begin{array}{l}\mathrm{CHCl}_{3} \\
\mathrm{NaClO}\end{array}$ & $\begin{array}{l}100 \\
89\end{array}$ & $\begin{array}{l}265 \\
260\end{array}$ & $\begin{array}{l}291 \\
280\end{array}$ & \multirow[t]{9}{*}{ This study } \\
\hline \multirow[t]{2}{*}{ B 2-a } & & \multirow[t]{2}{*}{ Thermal drying } & $\mathrm{CHCl}_{3}$ & 98 & 278 & 303 & \\
\hline & & & $\mathrm{NaClO}$ & 90 & 265 & 284 & \\
\hline \multirow[t]{2}{*}{ B 3-a } & & \multirow[t]{2}{*}{ Thermal dying } & $\mathrm{CHCl}_{3}$ & 97 & 277 & 301 & \\
\hline & & & $\mathrm{NaClO}$ & 74 & 265 & 287 & \\
\hline \multirow[t]{2}{*}{ B 4-a } & & \multirow[t]{2}{*}{ Thermal drying } & $\mathrm{CHCl}_{3}$ & 97 & 271 & 290 & \\
\hline & & & $\mathrm{NaClO}$ & 75 & 254 & 269 & \\
\hline \multirow[t]{2}{*}{ B 5-a } & & \multirow[t]{2}{*}{ Thermal drying } & $\mathrm{CHCl}_{3}$ & 83 & 267 & 298 & \\
\hline & & & $\mathrm{NaClO}$ & 100 & 252 & 272 & \\
\hline B $1-b$ & OFMSW-WAS mixture & Wet acidification & $\mathrm{NaClO}$ & 100 & 268 & 289 & This study \\
\hline B 2-b & & Wet acidification & $\mathrm{NaClO}$ & 99 & 270 & 293 & \\
\hline MMC-PHA & Synthetic VFA mix & - & $\mathrm{NaClO}$ & - & - & $281-291$ & {$[26]$} \\
\hline MMC-PHA & Synthetic VFA mix & - & $\mathrm{HClO}$ & - & - & $267-273$ & {$[18]$} \\
\hline MMC-PHA & WAS & Freeze-drying & $\mathrm{CHCl}_{3}$ & - & - & 275 & {$[36]$} \\
\hline MMC-PHA & WAS & Drying & $\mathrm{CH}_{3} \mathrm{CH}_{2} \mathrm{CH}(\mathrm{OH}) \mathrm{CH}_{3}$ & - & - & 291 & {$[33]$} \\
\hline MMC-PHA & Molasses & - & $\mathrm{CHCl}_{3}$ & - & - & $277-291$ & {$[17]$} \\
\hline
\end{tabular}

${ }^{\text {a }}$ Acid-stabilized wet biomass

As a main result, $\mathrm{NaClO}$ digestion did not affect the molecular weight for thermally stabilized samples. In fact, the $M_{v}$ values of all the five batches (B1-a, B2-a, B3-a, B4-a, B5-a) are comparable: $127 \pm 16$ and $132 \pm 10 \mathrm{kDa}$ for $\mathrm{NaClO}-$ and $\mathrm{CHCl}_{3}$-extracted samples, respectively. Moreover, the $M_{v}$ determination allowed to evidence any possible effects of the biomass pre-treatment on the PHA by the comparison between $M_{v}$ of thermally stabilized and the acid-stabilized samples. Indeed, a $\mathrm{NaClO}$ digestion has been conducted on an acid-stabilized wet biomass in order to skip the drying step and better understand the differences between the two stabilization methods. As reported in Fig. 3, the two samples B1-b and B2-b show that after extraction, carried out following the same operative conditions of the previous samples, the polymer recovered from acid-stabilized biomass has a significantly

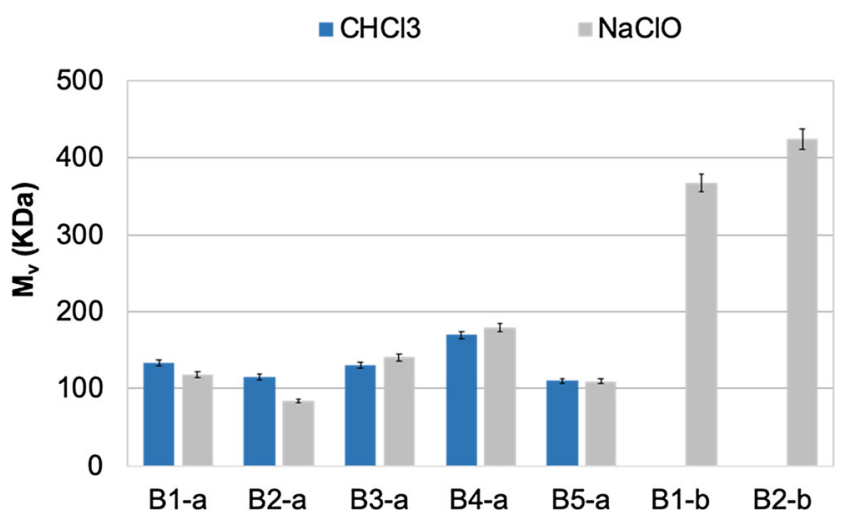

Fig. 3 Viscosimetry average molecular weight of extracted PHA (chloroform and hypochlorite) from thermally stabilized (series "a") and acid-stabilized (series "b") biomass higher molecular weight ( 370 and $424 \mathrm{kDa}$, respectively) than that obtained from thermal treatment. This evidence is a confirmation of the effective capacity of acidification to stabilize PHA for downstream processing without affecting its molecular weight [24]. It is general knowledge that $M_{v}$ depends on PHA chemical stability, which in turn may be strongly affected by chemical impurities [24]. The impurities may be organic (proteins, carbohydrates, and lipids) and/or inorganic (cations such as calcium, magnesium, sodium, and corresponding anions such as phosphate, sulfate, and chloride), and they are components found in the NPCM. The chemical stability of recovered PHA can be improved by removing the impurities; in particular, the acidification method allowed to solubilize ions associated with the biomass. Thereafter, dewatering and separating the ions from the PHA-rich biomass may have improved the PHA stability in the following extraction procedure. In addition, by decreasing the $\mathrm{pH}$ to 2.0 , the microbial activity was immediately inhibited. This synergistic effect may have contributed to increase the chemical PHA stability, giving (after the extraction) a $M_{v}$ roughly three times higher than $M_{v}$ obtained with thermally stabilized biomass.

Contrary to what has been reported in previous studies [34, 35], there is no correlation between the molecular weight and the HV content. It is also true that recent examples of MMCPHA produced from wastes and/or synthetic VFA mixture do not show a correlation between the $M_{w}$ and the HV content in the copolymer [36, 37]. According to literature data, the commercial polymers from pure culture systems exhibit a wide range of molecular weight $\left(M_{w}\right): 200-660 \mathrm{kDa}$ (similar to the $M_{v}$ of PHA from wet acid-stabilized biomass); in this 
range, higher $M_{w}$ values were related to the P-3HB homopolymer [33, 38]. On the contrary, it is often reported that MMC is able to produce PHA with higher $M_{w}$ than these obtained in this study. Previous studies reported $M_{w}$ of $340-540 \mathrm{kDa}$ [26] and $440-630 \mathrm{kDa}$ [15] for PHA produced from synthetic VFA mixture, 400-600 kDa [39] from crude glycerol fermentation liquid, $800 \mathrm{kDa}$ [38] from percolates of the OFMSW, and $650 \mathrm{kDa}$ [36] from WAS. There are also examples with similar or even lower $M_{w}$ values compared with those ones obtained in this study: $110-250 \mathrm{kDa}$ [37] from cheese whey and olive mill wastewater and 100-200 kDa [39] from crude glycerol fermentation liquid. All these data, however, have been collected from laboratory-scale equipment. Very few examples have reported PHA production and characterization from larger plant dedicated to waste management and services of wastewater treatment. In this context, PHA with $M_{w}$ of 400 $500 \mathrm{kDa}$ has been produced from surplus full-scale activated sludge $[9,40]$. There are no examples describing the pilotscale MMC-PHA production and characterization from OFMSW-WAS mixture as carbon source.

\subsection{DSC analysis}

The DSC profiles of the first and second heating of B1-a sample is reported in Fig. 4.

The thermograms of the other samples do not remarkably change from that of B1-a.

The absence of the exothermic peak in the DSC thermograms of the second heating, due to cold crystallization, reveals that the sample reached the maximum crystallinity during the isothermal stage at $70{ }^{\circ} \mathrm{C}$. In both thermograms, the main transition is the melting process occurring in the 130 $175{ }^{\circ} \mathrm{C}$ temperature range. The double endothermic peak could be due to the melting of thin crystals, recrystallization, and remelting of the thickened crystals during the heating or to the presence of different crystal modification. However, the small but clear exothermic process between the two melting peaks in the first heating lets prevail the first possible

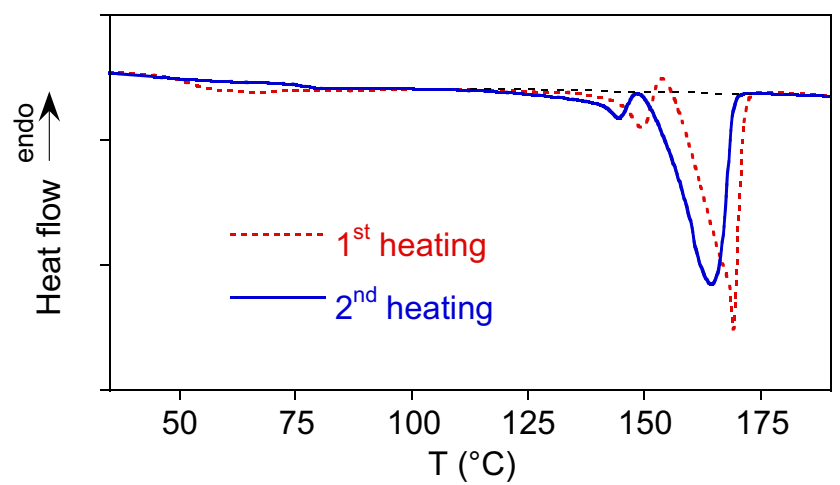

Fig. 4 First and second heating DSC thermograms recorded at $10^{\circ} \mathrm{C} / \mathrm{min}$ of the sample B1-a. The dashed line is the baseline used to evaluate the integral enthalpy of the melting process mechanism. Analog interpretation has been given by de Koning et al. [41].

The low temperature transition at about $65{ }^{\circ} \mathrm{C}$ (first heating) and $75{ }^{\circ} \mathrm{C}$ (second heating) could be assigned to a small copolymer fraction characterized by a high $3 \mathrm{HV}$ content [42]. The values of the first $\left(T_{m}{ }^{1}\right)$ and second $\left(T_{m}{ }^{2}\right)$ melting peak as well as the enthalpy of fusion $\left(\Delta H_{m}\right)$ of each sample are reported in Table 3.

From the integrated melting enthalpy, the sample crystallinity was evaluated by Eq. 2 and reported in Fig. 5 as a function of the $3 \mathrm{HB}$ molar content.

The possible variation related to the process operation at pilot scale such as the unavoidable fluctuations of the operating conditions (e.g., organic loading rate, microbial storage response, etc.) could have brought to differences in the PHA synthesis and, as a consequence, in the scattering of the data obtained from the first DSC heating scan. On the other hand, the results of the second run clearly show that the crystallinity linearly increased with the $3 \mathrm{HB}$ content in the copolymer. Since the polymer was produced over a wide window time, possible variation of the selected microbial community could have brought to some differences in the copolymer microstructure and, as a consequence, to different thermal behavior. In fact, the PHA properties are not only determined by the monomer composition but also by the mechanisms of substrate consumption and polymer synthesis, which are strictly related to the type of selected microorganisms [17]. However, the results of the second run are good in agreement with the data reported in literature for $3 \mathrm{HB}$ concentration higher than about $50 \mathrm{~mol} \%$ [17, 43]. This let infer that the PHA samples, obtained in different accumulation processes, besides the composition, did not differ in overall chemical structure. A comparison with previous MMC-PHA samples produced from synthetic VFA mixture and other waste streams shows the similarity of both melting temperatures and enthalpy with values of OFMSW-WAS-derived polymer (Table 3).

\subsection{Potential applications}

Experiences of a consistent carbon source availability and MMC-PHA synthesis under conditions of routine production are a necessary step for defining the product applications. A wider PHA characterization and the development of bioplastic formulations require high amount of material. Even at kilograms order at pilot scale are still insufficient for compounders and/or product-market developers [6]. However, from the screening of data obtained in this study, a first evaluation can be made.

For commodity applications, three mechanical properties are generally considered [1]: the elongation at break, the Young's modulus, and tensile strength. The manipulation of this properties is generally required for reducing the material's brittleness, which has been a reported as obstacle for PHA 
Table 3 Thermal properties of the samples measured in the first and second DSC heating scan

\begin{tabular}{|c|c|c|c|c|c|c|c|c|}
\hline \multirow[t]{2}{*}{ Sample } & \multirow[t]{2}{*}{ Feedstock } & \multicolumn{3}{|c|}{ First heating } & \multicolumn{3}{|c|}{ Second heating } & \multirow[t]{2}{*}{ References } \\
\hline & & $T_{m}{ }^{1}\left({ }^{\circ} \mathrm{C}\right)$ & $T_{m}^{2}\left({ }^{\circ} \mathrm{C}\right)$ & $\begin{array}{l}\Delta H_{m} \\
(\mathrm{~J} / \mathrm{g})\end{array}$ & $\begin{array}{l}T_{m}{ }^{1} \\
\left({ }^{\circ} \mathrm{C}\right)\end{array}$ & $\begin{array}{l}T_{m}{ }^{2} \\
\left({ }^{\circ} \mathrm{C}\right)\end{array}$ & $\begin{array}{l}\Delta H_{m} \\
(\mathrm{~J} / \mathrm{g})\end{array}$ & \\
\hline B1-a & \multirow{5}{*}{$\begin{array}{l}\text { OFMSW-WAS } \\
\text { mixture }\end{array}$} & 150 & 169 & 45 & 144 & 164 & 54 & \multirow[t]{5}{*}{ This study } \\
\hline B2-a & & 143 & 159 & 66 & 143 & 158 & 70 & \\
\hline B3-a & & 139 & 157 & 32 & 132 & 155 & 55 & \\
\hline B4-a & & 147 & 167 & 58 & 150 & 167 & 60 & \\
\hline B5-a & & 141 & 160 & 26 & 134 & 157 & 42 & \\
\hline MMC-PHA & WAS & 136 & 144 & 24 & & & & [36] \\
\hline MMC-PHA & Cheese whey & $126-147$ & $144-163$ & & & & & {$[37]$} \\
\hline MMC-PHA & $\begin{array}{l}\text { Olive mill } \\
\text { wastewater }\end{array}$ & 133 & 150 & & & & & [37] \\
\hline MMC-PHA & Molasses & $129-154$ & $144-165$ & $5-17$ & & & & [17] \\
\hline MMC-PHA & $\begin{array}{l}\text { Synthetic VFA } \\
\text { mix }\end{array}$ & & $143-168$ & $1-78$ & & & & {$[15]$} \\
\hline MMC-PHA & $\begin{array}{l}\text { Synthetic VFA } \\
\text { mix }\end{array}$ & 89-174 & $150-172$ & $20-82$ & & & & [17] \\
\hline
\end{tabular}

application. At this stage, the available amount of PHA did not allow to set the required tests. However, the composition of synthetized PHA (roughly 7-20 wt\% 3HV content) could mean good stiffness, improved toughness (and/or brittleness), and increased flexibility to pure $\mathrm{P}(3 \mathrm{HB})$ usually produced by pure culture. It is also true that the PHA mechanical properties may deteriorate when the $M_{w}$ is lower than $400 \mathrm{kDa}$, and for thermoplastic applications, the $M_{w}$ should be higher or equal to $600 \mathrm{kDa}$ [1]. Hence, the PHA extracted from thermally stabilized biomass is undoubtedly unsuitable for thermoplastic applications; on the contrary, the PHA derived from wetacidified biomass deserves further investigation.

One of the market scenarios which could not require PHA at high $M_{w}$ (or eventually at a level of purity lower than 98$100 \mathrm{wt} \%)$ is the groundwater remediation with permeable

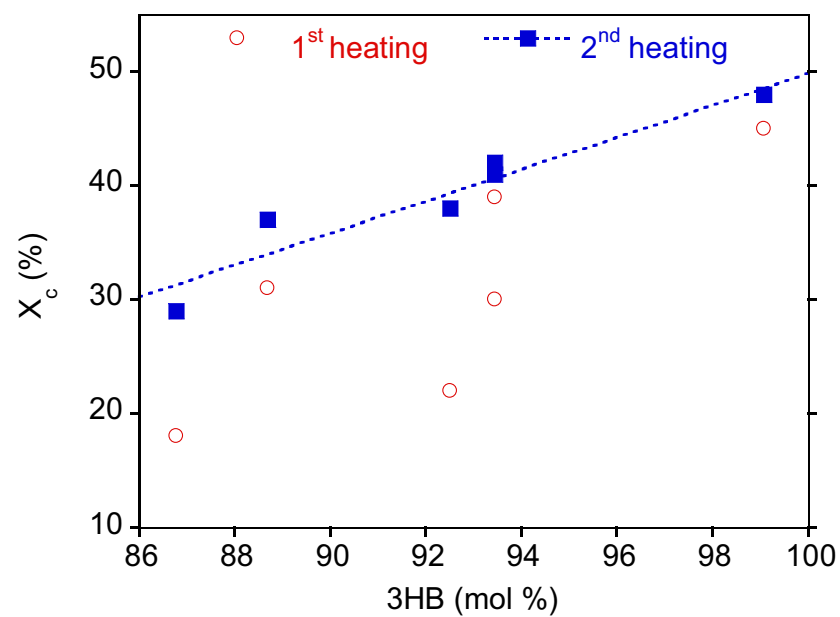

Fig. 5 Sample crystallinity measured in the first and second DSC heating scan as a function of the $3 \mathrm{HB}$ molar content in the copolymer samples. The dashed line is a guide for the eyes reactive barriers (PRBs) where zero-valent iron (ZVI) is employed as reactive media for treating plumes polluted by chlorinated hydrocarbons [44]. The patented PRB-ZVI technology needs a long-lasting slow-release organic source (e.g., PHA) to enhance the degradation performance of ZVI barriers, stimulating the biological reductive dechlorination of the PRB [45].

The future commercial developments need to include fundamental advancement in the downstream processing, which in turn requires a demonstration production scale (in the order of tons of PHA produced per year). This is necessary for the material processing and definition of market applications.

\section{Conclusions}

The present work showed the importance of applying an adequate and efficient stabilization method on a PHA-rich biomass, in order to preserve the properties and the amount of the polymer before the downstream processing. At the end of the accumulation step conducted at pilot scale, thermal treatment and acidification lead to a complete biomass inhibition and stabilization of the PHA amount. However, only acidifying the PHA-rich biomass allowed to recover a high molecular weight polymer (370-424 kDa). Moreover, no correlation has been found among $3 \mathrm{HV}$ content and molecular weight, while the crystallinity of the PHA was significantly affected by the copolymer composition $[1,43]$. Further investigation on extraction and characterization of PHA from acidified biomass is needed. More thorough analysis has to be carried out for the determination of thermal and mechanical properties of the more recently produced polymer. 
In fact, up to now, studies have been focused on correlations between process parameters, feeding strategies, and final mechanical properties for mixed culture PHA, but researches on the characterization of PHA from OFMSW and WAS are still missing. Thanks to the very recent diffusion of pilot-scale processes involving solid wastes for PHA production, it is now important to demonstrate that the chemomechanical properties are comparable with those of pure culture PHA and can be modulated on the basis of future applications.

Funding information This work was supported by the REsources from URban BIo-waSte-RES URBIS (GA 7303499) project in the European Horizon 2020 (Call CIRC-05-2016) program.

Open Access This article is licensed under a Creative Commons Attribution 4.0 International License, which permits use, sharing, adaptation, distribution and reproduction in any medium or format, as long as you give appropriate credit to the original author(s) and the source, provide a link to the Creative Commons licence, and indicate if changes were made. The images or other third party material in this article are included in the article's Creative Commons licence, unless indicated otherwise in a credit line to the material. If material is not included in the article's Creative Commons licence and your intended use is not permitted by statutory regulation or exceeds the permitted use, you will need to obtain permission directly from the copyright holder. To view a copy of this licence, visit http://creativecommons.org/licenses/by/4.0/.

\section{References}

1. Laycock B, Halley P, Pratt S, Werker A, Lant P (2013) The chemomechanical properties of microbial polyhydroxyalkanoates. Prog Polym Sci 38:536-583. https://doi.org/10.1016/j. progpolymsci.2012.06.003

2. Ong SY, Chee JY, Sudesh K (2017) Degradation of polyhydroxyalkanoate (PHA): a review. J Sib Fed Univ Biol 10: 211-225. https://doi.org/10.17516/1997-1389-0024

3. Weng YX, Wang XL, Wang YZ (2011) Biodegradation behavior of PHAs with different chemical structures under controlled composting conditions. Polym Test 30:372-380. https://doi.org/ 10.1016/j.polymertesting.2011.02.001

4. Cinelli P, Seggiani M, Mallegni M, Gigante V, Lazzeri A (2019) Processability and degradability of PHA-based composites in terrestrial environments. Int J Mol Sci 20:284. https://doi.org/10.3390/ ijms20020284

5. Reis MAM, Albuquerque M, Villano M, Majone M, (2011) Mixed culture processes for polyhydroxyalkanoate production from agroindustrial surplus/wastes as feedstocks. Compr Biotechnol 669683. https://doi.org/10.1016/B978-0-08-088504-9.00464-5

6. Valentino F, Morgan-Sagastume F, Campanari S, Villano M, Werker A, Majone M (2017) Carbon recovery from wastewater through bioconversion into biodegradable polymers. New Biotechnol 37:9-23. https://doi.org/10.1016/j.nbt.2016.05.007

7. Dionisi D, Majone M, Vallini G, Di Gregorio S, Beccari M (2006) Effect of the applied organic load rate on biodegradable polymer production by mixed microbial cultures in a sequencing batch reactor. Biotechnol Bioeng 93:76-88. https://doi.org/10.1002/bit. 20683

8. Bengtsson S, Karlsson A, Alexandersson T, Quadri L, Hjort M, Johansson P, Morgan-Sagastume F, Anterrieu S, Arcos-Hernandez M, Karabegovic L, Magnusson P, Werker A (2017) A process for polyhydroxyalkanoate (PHA) production from municipal wastewater treatment with biological carbon and nitrogen removal demonstrated at pilot-scale. New Biotechnol 35:42-53. https://doi.org/10. 1016/j.nbt.2016.11.005

9. Werker A, Bengtsson S, Korving L, Hjort M, Anterrieu S, Alexandersson T, Johansson P, Karlsson A, Karabegovic L, Magnusson P, Morgan-Sagastume F, Sijstermans L, Tietema M, Visser C, Wypkema E, Van Der Kooij Y, Deeke A, Uijterlinde C (2018) Consistent production of high quality PHA using activated sludge harvested from full scale municipal wastewater treatmentPHARIO. Water Sci Technol 78:2256-2269. https://doi.org/10. 2166/wst.2018.502

10. Valentino F, Gottardo M, Micolucci F, Pavan P, Bolzonella D, Rossetti S, Majone M (2018) Organic fraction of municipal solid waste recovery by conversion into added-value polyhydroxyalkanoates and biogas. ACS Sustain Chem Eng 6: 16375-16385. https://doi.org/10.1021/acssuschemeng.8b03454

11. Valentino F, Moretto G, Lorini L, Bolzonella D, Pavan P, Majone M (2019) Pilot-scale polyhydroxyalkanoate production from combined treatment of organic fraction of municipal solid waste and sewage sludge. Ind Eng Chem Res 58:12149-12158. https://doi. org/10.1021/acs.iecr.9b01831

12. Moretto G, Russo I, Bolzonella D, Pavan P, Majone M, Valentino F (2020) An urban biorefinery for food waste and biological sludge conversion into polyhydroxyalkanoates and biogas. Water Res 170: 115371. https://doi.org/10.1016/j.watres.2019.115371

13. Pérez-Rivero C, López-Gómez JP, Roy I (2019) A sustainable approach for the downstream processing of bacterial polyhydroxyalkanoates: state-of-the-art and latest developments. Biochem Eng J 150:107283. https://doi.org/10.1016/j.bej.2019. 107283

14. Werker AG, Johansson PST, Magnusson POG (2014) Process for the extraction of polyhydroxyalkanoates from biomass. WO2014125422A1 Patent

15. Laycock B, Arcos-Hernandez MV, Langford A, Pratt S, Werker A, Halley PJ, Lant PA (2014) Crystallisation and fractionation of selected polyhydroxyalkanoates produced from mixed cultures. New Biotechnol 31:345-356. https://doi.org/10.1016/j.nbt.2013.05.005

16. Bengtsson S, Pisco AR, Reis MAM, Lemos PC (2010) Production of polyhydroxyalkanoates from fermented sugar cane molasses by a mixed culture enriched in glycogen accumulating organisms. J Biotechnol 145:253-263. https://doi.org/10.1016/j.jbiotec.2009. 11.016

17. Bengtsson S, Pisco AR, Johansson P, Lemos PC, Reis MAM (2010) Molecular weight and thermal properties of polyhydroxyalkanoates produced from fermented sugar molasses by open mixed cultures. J Biotechnol 147:172-179. https://doi.org/ 10.1016/j.jbiotec.2010.03.022

18. Carrasco F, Dionisi D, Martinelli A, Majone M (2006) Thermal stability of polyhydroxyalkanoates. J Appl Polym Sci 100:21112121. https://doi.org/10.1002/app.23586

19. Arcos-Hernández MV, Laycock B, Donose BC, Pratt S, Halley P, Al-Luaibi S, Werker A, Lant PA (2013) Physicochemical and mechanical properties of mixed culture polyhydroxyalkanoate (PHBV). Eur Polym J 49:904-913. https://doi.org/10.1016/j. eurpolymj.2012.10.025

20. Majone M, Chronopoulou L, Lorini L, Martinelli A, Palocci C, Rossetti S, Valentino F, Villano M (2017) PHA copolymers from microbial mixed cultures: synthesis, extraction and related properties. In Koller M (ed) Current advances in biopolymer processing and characterization, Nova Science Publishers, Inc., Elsevier B.V., pp 223-276

21. Braunegg G, Sonnleitner B, Lafferty R (1978) Rapid gaschromatographic method for determination of poly-betahydroxybutyric acid in microbial biomass. Bioetchnol Bioeng 6: 29-37. https://doi.org/10.1007/BF00500854 
22. Marchessault RH, Okamura K, Su CJ (1970) Physical properties of poly ( $\beta$-hydroxy butyrate). II Conformational Aspects in Solution. Macromolecules 3:735-740. https://doi.org/10.1021/ma60018a005

23. Barham PJ, Keller A, Otun EL, Holmes PA (1984) Crystallization and morphology of a bacterial thermoplastic: poly-3hydroxybutyrate. J Mater Sci 19:2781-2794. https://doi.org/10. 1007/BF01026954

24. Werker AG, Johansson PST, Magnusson POG, Maurer FHJ, Jannasch P (2012) Method for recovery of stabilized polyhydroxyalkanoates from biomass that has been used to treat organic waste. WO2012022998A1 patent

25. Jiang Y, Mikova G, Kleerebezem R, van der Wielen LAM, Cuellar MC (2015) Feasibility study of an alkaline-based chemical treatment for the purification of polyhydroxybutyrate produced by a mixed enriched culture. AMB Express 5:5. https://doi.org/10. 1186/s13568-015-0096-5

26. Villano M, Valentino F, Barbetta A, Martino L, Scandola M, Majone M (2014) Polyhydroxyalkanoates production with mixed microbial cultures: from culture selection to polymer recovery in a high-rate continuous process. New Biotechnol 31:289-296. https:// doi.org/10.1016/j.nbt.2013.08.001

27. Serafim LS, Lemos PC, Albuquerque MGE, Reis MAM (2008) Strategies for PHA production by mixed cultures and renewable waste materials. Appl Microbiol Biotechnol 81:615-628. https:// doi.org/10.1007/s00253-008-1757-y

28. Lemos PC, Viana C, Salgueiro EN, Ramos AM, Crespo JPSG, Reis MAM (1998) Effect of carbon source on the formation of polyhydroxyalkanoates (PHA) by a phosphate-accumulating mixed culture. Enzym Microb Technol 22:662-671. https://doi.org/10. 1016/S0141-0229(97)00243-3

29. Patel M, Gapes DJ, Newman RH, Dare PH (2009) Physicochemical properties of polyhydroxyalkanoate produced by mixedculture nitrogen-fixing bacteria. Appl Microbiol Biotechnol 82: 545-555. https://doi.org/10.1007/s00253-008-1836-0

30. Albuquerque MGE, Martino V, Pollet E, Avérous L, Reis MAM (2011) Mixed culture polyhydroxyalkanoate (PHA) production from volatile fatty acid (VFA)-rich streams: effect of substrate composition and feeding regime on PHA productivity, composition and properties. J Biotechnol 151:66-76. https://doi.org/10.1016/j. jbiotec.2010.10.070

31. Samorì C, Abbondanzi F, Galletti $\mathrm{P}$, Giorgini L, Mazzocchetti L, Torri C, Tagliavini E (2015) Extraction of polyhydroxyalkanoates from mixed microbial cultures: impact on polymer quality and recovery. Bioresour Technol 189:195-202. https://doi.org/10.1016/j. biortech.2015.03.062

32. Hahn SK, Chang YK (1995) A themogravimetric analysis for poly(3-hydroxybutyrate) quantification. Biotechnol Tech 9:873878. https://doi.org/10.1007/BF00158539

33. Morgan-Sagastume F, Hjort M, Cirne D, Gérardin F, Lacroix S, Gaval G, Karabegovic L, Alexandersson T, Johansson P, Karlsson A, Bengtsson S, Arcos-Hernández MV, Magnusson P, Werker A (2015) Integrated production of polyhydroxyalkanoates (PHAs) with municipal wastewater and sludge treatment at pilot scale. Bioresour Technol 181:78-89. https://doi.org/10.1016/j.biortech. 2015.01.046

34. Johnson K, Jiang Y, Kleerebezem R, Muyzer G, van Loosdrecht M (2009) Enrichment of a mixed bacterial culture with a high polyhydroxyalkanoate storage capacity. Biomacromolecules 10: 670-676. https://doi.org/10.1021/bm8013796

35. Johnson K, Kleerebezem R, van Loosdrecht MCM (2010) Influence of the $\mathrm{C} / \mathrm{N}$ ratio on the performance of polyhydroxybutyrate (PHB) producing sequencing batch reactors at short SRTs. Water Res 44:2141-2152. https://doi.org/10.1016/j. watres.2009.12.031

36. Frison N, Katsou E, Malamis S, Oehmen A, Fatone F (2015) Development of a novel process integrating the treatment of sludge reject water and the production of polyhydroxyalkanoates (PHAs). Environ Sci Technol 49:10877-10885. https://doi.org/10.1021/acs. est. 5 b01776

37. Hilliou L, Machado D, Oliveira CSS, Gouveia AR, Reis MAM, Campanari S, Villano M, Majone M (2016) Impact of fermentation residues on the thermal, structural, and rheological properties of polyhydroxy(butyrate-co-valerate) produced from cheese whey and olive oil mill wastewater. J Appl Polym Sci 133:42818. https://doi.org/10.1002/app.42818

38. Colombo B, Favini F, Scaglia B, Sciarria TP, D'Imporzano G, Pognani M, Alekseeva A, Eisele G, Cosentino C, Adani F (2017) Enhanced polyhydroxyalkanoate (PHA) production from the organic fraction of municipal solid waste by using mixed microbial culture. Biotechnol Biofuels 10:201. https://doi.org/10.1186/ s13068-017-0888-8

39. Burniol-Figols A, Skiadas IV, Daugaard AE, Gavala HN (2019) Polyhydroxyalkanoate (PHA) purification through dilute aqueous ammonia digestion at elevated temperatures. J Chem Technol Biotechnol 95:1519-1532. https://doi.org/10.1002/jctb.6345

40. Arcos-Hernández M, Montaño-Herrera L, Janarthanan OM, Quadri L, Anterrieu S, Hjort M, Alexandersson T, Karlsson A, Karabegovic L, Magnusson P, Johansson P, Bengtsson S, Morgan-Sagastume F, de Vegt O, Laycock B, Pratt S, Halley P, Lant P, Werker A (2015) Value-added bioplastics from services of wastewater treatment. Water Pract Technol 10:546-555. https://doi. org/10.2166/wpt.2015.063

41. de Koning GJM, Scheeren AHC, Lemstra PJ, Peeters M, Reynaers $\mathrm{H}$ (1994) Crystallization phenomena in bacterial poly[(R)-3hydroxybutyrate]: 3 . Toughening via texture changes. Polymer (Guildf) 35:4598-4605. https://doi.org/10.1016/0032-3861(94) 90809-5

42. Laycock B, Arcos-Hernandez M, Langford A, Buchanan J, Halley PJ, Werker A, Lant PA, Pratt S (2014) Thermal properties and crystallization behavior of fractionated blocky and random polyhydroxyalkanoate copolymers from mixed microbial cultures. J Appl Polym Sci. https://doi.org/10.1002/app.40836

43. Wang Y, Yamada S, Asakawa N, Yamane T, Yoshie N, Inoue Y (2001) Comonomer compositional distribution and thermal and morphological characteristics of bacterial poly(3-hydroxybutyrateco-3-hydroxyvalerate)s with high 3-hydroxyvalerate content. Biomacromolecules 2:1315-1323. https://doi.org/10.1021/ bm0101280

44. Baric M, Pierro L, Pietrangeli B, Petrangeli Papini M (2014) Polyhydroxyalkanoate (PHB) as a slow-release electron donor for advanced in situ bioremediation of chlorinated solventcontaminated aquifers. New Biotechnol 31:377-382. https://doi. org/10.1016/j.nbt.2013.10.008

45. Petrangeli papini M, Majone M, Baric M, Pierro L (2015) Process, arrangement and plant for the clean-up of waters contaminated by chlorinated solvents, nitrates and sulphates. WO2015162527A1 Patent

Publisher's Note Springer Nature remains neutral with regard to jurisdictional claims in published maps and institutional affiliations. 